\title{
Breast Cancer in Iranian Woman: Incidence by Age Group, Morphology and Trends
}

\author{
Hosein Rafiemanesh ${ }^{1}$, Hamid Salehiniya ${ }^{2,3}$, Zahra Lotfi ${ }^{2 *}$
}

\begin{abstract}
Background: Breast cancer is the most common cancer and the first cause of cancer death in women worldwide, with infiltrating duct carcinoma as the most common morphology. This study aimed to investigate trend of breast cancer incidence by age groups and histological changes in Iranian women between 2003 and 2008. Materials and Methods: This is analytic study, carried out based on re-analysis of the Cancer Registry Center report of health deputy for women's breast cancer in Iran during a 6-year period (2003-2008). Statistical analysis for incidence time trends and morphology change percentage carried out joinpoint regression analysis using the software Joinpoint Regression Program. Results: A total of 36,340 cases were reported for Iranian women in the six years. Analytical trend showed an increasing incidence trend with significant annual percentage change (APC) of 15.2 (CI: 11.6 to 18.8). The lowest and highest significant increased trend were related to age groups of 40 to 44 years and above 85 years, respectively; with APCs of 13.0 and 25.1, respectively. Of total cases, $78.7 \%$ of cases were infiltrating duct carcinoma, decreasing from $82.0 \%$ in 2003 to $76.6 \%$ in 2008, which was significant with an APC equal to -1.76 (CI:-2.7 to -0.8). Conclusions: The incidence trend of breast cancer is rising in Iranian women. The highest incidence was observed in the age groups 45-65 and 80-85. In conclusion, to reduce breast cancer incidence and its burden, preventive and screening programs for breast cancer, especially in young women, are recommended in Iran.
\end{abstract}

Keywords: Breast cancer - incidence - trend - pathology - Iranian women

Asian Pac J Cancer Prev, 17 (3), 1393-1397

\section{Introduction}

In the $21^{\text {st }}$ century, all countries has encountered with the fundamental problem of cancer, which is the third cause of death in the world and according to estimates of GLOBOCAN, approximately 12.7 million new cancer cases and 7.6 million cancer deaths occurred in 2008(Jemal et al., 2011). It is predicted to increase annual new cases from 10 million in 2000 to 15 million in 2020 . However, the epidemiologic pattern of cancer showed main differences between developed and developing countries. Almost $60 \%$ of all cancer was seen in developing countries (Vakili et al., 2014) and incidence and morphology trend of cancers is changing in the different countries (Jemal et al., 2010; Almasi et al., 2015; Keyghobadi et al., 2015; Rafiemanesh et al., 2015a; Rafiemanesh et al., 2015b; Razi et al., 2015).

Breast cancer is the most common cancer and the first cause of cancer death in women worldwide. In the past decade, the most common cancer was cervical cancer among women. In 2008, breast cancer took account for $23 \%$ (1380000 cases) of all new cases and 14\% (458400 cases) of all cancer deaths in the world. About half of incidence cases and $60 \%$ of mortality occur in developing countries. The highest incidence was observed in West and North of Europe, Australia, New Zealand, and North America (Jemal et al., 2011). Age-Standardized Incidence Rate (ASIR) was different from 19.3 per 100,000 in East of Africa to 89.9 per 100,000 in West of Africa. Overall, in developed countries, ASR was more than 80 per 100,000, but in developing countries less than 40 per 100,000 . The incidence rate of breast cancer is 39 per 100,000 in women in the world (Ferlay et al., 2010). The cancer is the most common cancer in Iranian women and the incidence rate was 24 per 100,000 in 2004 (Mousavi et al., 2009).

It seems that genetic factors constitute only 5-10\% of related risk factors to the cancer (Sasco, 2001; Chin et al., 2005; Anand et al., 2008) and 90-95\% of other risk factors include changing patterns of reproduction, lack of physical inactivity, and obesity (Jemal et al., 2011). It is expected to raise incidence of cancer cases due to changes in individual's lifestyle and an increase of life expectancy (Mousavi et al., 2009).

In many African and Asian countries, the incidence and mortality rates of breast cancer are increasing. However, increasing awareness of women and screening tests lead

${ }^{1}$ Department of Epidemiology and Biostatistics, School of Public Health, Shahid Beheshti University of Medical Sciences, ${ }^{2}$ Department of Epidemiology and Biostatistics, School of Public Health, Tehran University of Medical Sciences, ${ }^{3}$ Minimally Invasive Surgery Research Center, Iran University of Medical Sciences, Tehran, Iran. *For correspondence: zlotfi23@yahoo.com 
to diagnose more cases in the future (Jemal et al., 2011). It is expected to rise the cases in the next years because of increased life expectancy and changes in lifestyle and attitude to the Western lifestyle (Mousavi et al., 2009).

A similar study in Iran showed that the incidence is increasing in the age groups 40-44, 45-49 and 55-59 years, with an average annual increase of $6.2 \%, 3.5 \%$, and $5.3 \%$, respectively (Tazhibi et al., 2014). Another study in Oman indicated that the highest ASIR was related to age groups of 45-54 years and 70-74 years, respectively (Mehdi et al., 2014).

Considering studies performed worldwide, INFILTRATING DUCT CARCINOMA is most common morphology of the cancer (Li et al., 2003; Chahine et al., 2015; Saxena et al., 2005). Studies in Iran reported that INFILTRATING DUCT CARCINOMA is also most common morphology of the cancer (Li et al., 2003; Mousavi et al., 2007; Naghibi et al., 2013).

There is a population-based cancer registry program in Iran. It is possible to detect common cancers and planning for control them using the accurate data. Awareness of the prevalent morphology can help diagnose and treatment of breast cancer cases, and investigate the stages of the disease. This study aimed to investigate trend of breast cancer incidence by age groups and histological changes in Iranian women between 2003 and 2008.

\section{Materials and Methods}

\section{Data source}

This is analytic study, carried out based on re-analysis national registry of cancer (NCR), and Disease Control and Prevention (CDC) report of ministry of Health and Medical Education in Iran. Deputy for health of each university is responsible for health issues of the population and all health activities are managed by these deputies. All deputies for health have been included in the NCR. Registrar would apply the national registration software which was developed by CDC. For pathologic centers, without software, the cancer records were gathered manually. The Cancer Office of CDC should provide techniques and funding supports. The data are transmitted every 3 months, by electronic file and also hard copy of 'Cancer Registry Data Collection Form'; this form is comprised of three parts: part I, regarding patient's identity characteristics in addition to the name of biopsy-taker physician, name of hospital, location of which the biopsy is taken, clinical diagnosis and date of biopsy sent to histological laboratory and demographic information of the patients includes race and residence. Part II includes the most important findings of patient's clinical history. Part III includes preclinical findings. The information includes primary location of tumor, date of cancer diagnosis, morphology and histology and its behavior and diagnosis method. Physicians fill the form of clinical data and the official personnel fill the identity and demographic information. Quality control has been coordinated in five main areas by Cancer Office of CDC: (i) regarding completeness of coverage; (ii) completeness of details; (iii) accuracy of data; (iv) accuracy of reports; (v) accuracy of interpretation and (vi) repeated cases are deleted from national data. Surveillance of pathology is based on the cancer record in several selected provinces to compare it with the present pathology cancer record for a general and complete evaluation and also for the accuracy of the collected data. IARC software provides a way to identify inaccuracies in data coding. Data were collected retrospectively reviewing all new women's breast cancer patients in Cancer Registry Center report of health deputy for Iran during a 6-year period (2003 - 2008) (Daubisse-Marliac et al., 2011). Accordance of The International Classification of Diseases for Oncology (ICD-OC: topography with ICDOM: morphology) Breast cancer was defined as ICD-O C50(AG., 2000). This study investigated all cases of the morphology of INFILTRATING DUCT CARCINOMA (8500/3), LOBULAR CARCINOMA, NOS (8520/3), MEDULLARY CARCINOMA, NOS (8510/3) and INTRADUCTALCARCINOMA, NONINFILTRATING, NOS (8500/2).

\section{Statistical analysis}

We calculated crude incidence rate (CIR) and the Agestandardized incidence rate (ASIR) per 100,000 persons. We used direct standardized method using world standard population(Santos, 1999). To describe incidence and age group incidence time trends, we use Age-standardized incidence rate (ASIR) and carried out joinpoint regression analysis using the software Joinpoint Regression Program, Version 4.1.1.1 October 2014 (Jemal et al., 2007). As well to evaluate the morphological changes, were obtained the percentage allocated for kind of morphological types. So to analysis morphology change percentage trends for six year, we carried out joinpoint regression analysis using the software Joinpoint Regression Program. The analysis included logarithmic transformation of the rates, maximum number of one joinpoints, and minimum of six years between zero joinpoints. All other program parameters were set to default values. The test of significance uses a Monte Carlo Permutation method (i.e., it finds "the best fit" line). joinpoint regression analysis involves fitting a series of joined straight lines on a log scale to the trends. The aim of the approach is to identify possible joinpoints where a significant change in the trend occurs. The final model selected was the most parsimonious of these, with the estimated annual percent change (APC) based on the trend within each segment. In describing trends, the terms "significant increase" or "significant decrease" signify

\section{Results}

A total of 36,340 cases were reported from Iranian women. The highest ASIR was seen at 45 to 65 years and 80 to 85 years, respectively (Figure 1 ).

Four histological types of, NONINFILTRATING, NOS, INTRADUCTAL CARCINOMA, INFILTRATING DUCT CARCINOMA, MEDULLARY CARCINOMA, NOS, and LOBULAR CARCINOMA included $89.56 \%$ of all morphologies.

Epidemiologic incidence Trend:

ASIR increased from 15.96 per 100,000 in 2003 
to 33.21 per 100,000 in 2008 . Analytical trend based on Joinpoint logarithmic scale showed an increasing incidence trend with significant Annual Percentage Changes (APC) of 15.15 (CI: 11.6 to18.8) (Table1).

The trend of incidence was increasing in age groups studied. The lowest and highest significant increased trend were related to age groups of 40 to 44 years and above 85 years, respectively; with APC of 12.95 and 25.07, respectively (Table2).

Table 1. Number of Cases, Crude Incidence Rate and Age-standardized Incidence Rates (per 100,000) between 2003 to 2008 .

\begin{tabular}{lccc}
\hline & N. & CIR & ASIR \\
\hline 2003 & 3946 & 12.19 & 15.96 \\
2004 & 4557 & 13.84 & 18.24 \\
2005 & 5981 & 17.44 & 23.16 \\
2006 & 6456 & 18.9 & 25.06 \\
2007 & 6976 & 20.42 & 27.15 \\
2008 & 8424 & 24.66 & 33.21 \\
\hline
\end{tabular}

CIR: crude incidence rate (per 100,000 persons); ASIR: Age-standardized incidence rate (per 100,000 persons)
DOI:http://dx.doi.org/10.7314/APJCP.2016.17.3.1393

Age-Dependent Trends of Breast Cancer Incidence in Iran Morphologic Trend

Of total cases, $78.71 \%$ of cases were INFILTRATING DUCT CARCINOMA, 5.37\% LOBULAR CARCINOMA, NOS, $2.77 \%$ MEDULLARY CARCINOMA, NOS, and $2.71 \%$ INTRADUCTAL CARCINOMA, NONINFILTRATING, NOS. the dedicated percentage was not same for four common morphologies. The most common morphology (INFILTRATING DUCT CARCINOMA) decreased from $81.98 \%$ in 2003 to



Figure 1. Age-Standardized Incidence Rate (ASIR) of breast cancers by 5 years age groups in Iranian woman in Iran, 2003-2003

Table 2. Incidence trends of breast cancers by 5 years age groups in Iranian woman in Iran, 2003-2008

\begin{tabular}{|c|c|c|c|c|c|c|}
\hline \multirow[b]{2}{*}{ Age group } & \multicolumn{2}{|c|}{ Full Range (2003-2008) } & \multicolumn{2}{|c|}{ Trend 1 (2003 -2005) } & \multicolumn{2}{|c|}{ Trend 2 (2005-2008) } \\
\hline & AAPC & $95 \% \mathrm{CI}$ & APC & $95 \% \mathrm{CI}$ & AAPC & $95 \% \mathrm{CI}$ \\
\hline $20-24 *$ & 17.9 & -2.3 to 42.3 & & & & \\
\hline $25-29 *$ & $14.8^{\wedge}$ & 2.9 to 28.1 & & & & \\
\hline $30-34 *$ & $13.1^{\wedge}$ & 10.9 to 15.4 & & & & \\
\hline $35-39 *$ & $14.3^{\wedge}$ & 8.1 to 20.9 & & & & \\
\hline $40-44 *$ & $12.9^{\wedge}$ & 10.1 to 15.9 & & & & \\
\hline $45-49^{*}$ & $13.8^{\wedge}$ & 9.7 to 18.0 & & & & \\
\hline $50-54 *$ & $16.5^{\wedge}$ & 10.6 to 22.6 & & & & \\
\hline $55-59 *$ & $17.2^{\wedge}$ & 13.2 to 21.3 & & & & \\
\hline $60-64 *$ & $18.4^{\wedge}$ & 12.7 to 24.4 & & & & \\
\hline $65-69^{*}$ & $13.5^{\wedge}$ & 9.8 to 17.2 & & & & \\
\hline $70-74 *$ & $13.0^{\wedge}$ & 8.4 to 17.7 & & & & \\
\hline $75-79 * *$ & $15.1^{\wedge}$ & 13.4 to 16.9 & $22.5^{\wedge}$ & 0.8 to 48.8 & $10.5^{\wedge}$ & 0.2 to 21.8 \\
\hline $80-84 *$ & $15.7^{\wedge}$ & 10 to 21.6 & & & & \\
\hline $85+* *$ & 23.8 & -0.9 to 54.7 & 0.6 & -94.4 to 1701.9 & 42.3 & -66.4 to 502.2 \\
\hline
\end{tabular}

${ }^{\wedge} \mathrm{APC}$ or AAPC is significantly different from zero at alpha $=0.05$; *Final selected model 0 Joinpoint(s);**Final selected model 1 Joinpoint(s)

Table 3. Morphology Trends of Breast Cancers Percentage Allocated to Four Common Morphology in Iranian Woman in Iran, 2003-2008

\begin{tabular}{|c|c|c|c|c|c|c|c|c|}
\hline \multirow[b]{2}{*}{ Morphology } & \multicolumn{5}{|c|}{ Frequency (Percent) } & \multicolumn{3}{|c|}{ Percent Trend 2003-2008 } \\
\hline & 2003 & 2004 & 2005 & 2006 & 2007 & 2008 & APC & $95 \% \mathrm{CI}$ \\
\hline \multicolumn{9}{|c|}{ Infiltrating Duct Carcinoma } \\
\hline & 3235 & 3782 & 4785 & 5037 & 5312 & 6452 & $-1.8^{\wedge}$ & -2.7 To -0.8 \\
\hline & $-81.98 \%$ & $-82.99 \%$ & $-80 \%$ & $-78.02 \%$ & $-76.15 \%$ & $-76.59 \%$ & & \\
\hline \multicolumn{9}{|c|}{ Lobular Carcinoma, Nos } \\
\hline & 182 & 218 & 347 & 361 & 385 & 460 & 3.6 & -1.3 To 8.8 \\
\hline & $-4.61 \%$ & $-4.78 \%$ & $-5.80 \%$ & $-5.59 \%$ & $-5.52 \%$ & $-5.46 \%$ & & \\
\hline \multicolumn{9}{|c|}{ Medullary Carcinoma, Nos } \\
\hline & 139 & 148 & 155 & 157 & 199 & 209 & -6.1 & -12.5 To 0.8 \\
\hline & $-3.52 \%$ & $-3.25 \%$ & $-2.59 \%$ & $-2.43 \%$ & $-2.85 \%$ & $-2.48 \%$ & & \\
\hline \multicolumn{9}{|c|}{ Intraductal Carcinoma, Noninfiltrating, Nos } \\
\hline & 96 & 89 & 133 & 119 & 303 & 243 & 9.1 & -10.6 To 33.2 \\
\hline & $-2.43 \%$ & $-1.95 \%$ & $-2.22 \%$ & $-1.84 \%$ & $-4.34 \%$ & $-2.88 \%$ & & \\
\hline
\end{tabular}

$\wedge \mathrm{APC}$ is significantly different from zero at alpha $=0.05$ 
$76.59 \%$ in 2008 , which was significant with APC equal to -1.76 (CI:-2.7to -0.8 ) (Table3).

\section{Discussion}

During 2003 to 2008,36340 cancer cases were reported from Iranian women. The trend of incidence rate in patients suffered from breast cancer showed a remarkable increase in all age groups. ASIR increased from 15.96 per 100,000 in 2003 to 33.21 per 100,000 in 2008. The result was different from findings of other studies (Naghibi et al., 2013). This may be due to difference in speed of lifestyle changes, especially in urban areas, and exposure to risk factors in various provinces. A similar study in China indicated such difference between urban and rural regions (Yang et al., 2015). In developed countries, AISR was more than 80 per 100,000 and in developing countries the rate was less than 40 per 100,000 , which consistent with our findings. In women in the world the incidence rate of breast cancer was 39 per 100,000 (Ferlay et al., 2010). However, the rate in Iranian women was similar to the rate worldwide. Another study on urban population in china revealed that ASIR increased from 26.53 per 100,000 between 1989 and 1999 to 42.92 per 100,000 between 2011 and 2012 (Yang et al., 2015), similar to our results.

Genetic factors include only 5 to $10 \%$ of related risk factors of breast cancer (Sasco, 2001; Chin et al., 2005; Anand et al., 2008), while 90 to $95 \%$ of the risk factors are changes in reproduction patterns, lack of physical activity, and obesity (Jemal et al., 2011). It is expected to enhance the number of breast cancer cases due to changes in lifestyle and increased life expectancy (Mousavi et al., 2009).

Studies on physical activity in Iran showed that lack of physical activity $n$ Iranian women, especially in older age groups, is more prevalent (Esteghamati et al., 2011). Considering that lack of physical activity is one of the risk factors for the cancer (Jemal et al., 2011), the cancer cases can be reduced through focus on the risk factor along with otheroperating programs.

Our findings determined a significant increasing incidence trend, with APC of 15.15. The greatest ASIR was observed in age groups of 45 to 65 years and 80 to 85 years, respectively. The highest incidence rate breast cancer was seen at 40 to 49 years between 1998 to 2005 in the country (Mousavi et al., 2007). Another study in Oman indicated that the highest ASIR was related to age groups of 45-54 years and 70-74 years, respectively (Mehdi et al., 2014). In a study in French, $66 \%$ of female patients were 50 to 74 years (Daubisse-Marliac et al., 2011).

In our study, the trend of breast cancer incidence was increasing. The lowest and highest significant increased trend were related to age groups of 40 to 44 years and above 85 years, respectively; with APC of 12.95 and 25.07 ,respectively. Results obtained from one of the provinces declared increased incidence rate in age groups of 40 to 44,45 to 49 , and 55 to 59 years, with the annual average increase of $6.2 \%, 3.5 \%$, and $5.3 \%$, respectively. There was also no difference in APC between age groups of 30 to 49 and 50 to 69 years (Tazhibi et al., 2014). This difference may be due to largeness of the region studied. In United States, 1990-1999, the invasive incidence breast cancer annually increased $1.2 \%$ and $4.8 \%$ from 1999 to 2003 , and then decreased $1.7 \%$. However, ASIR in women 45 years and above was decreasing between 1999 to 2003 . The lowest decrease was observed among women 55 to 59 years $(1.3 \%), 60$ to 64 years $(10.6 \%)$, and 65 to 69 years (14.3\%) during 2002 to 2003 (Jemal et al., 2007). This is opposite of our findings because a decrease in incidence of cases may be affected by preventive programs.

In this study, of all cases, $78.71 \%$ of cases were INFILTRATING DUCT CARCINOMA, 5.37\% LOBULAR CARCINOMA, NOS, 2.77\% MEDULLARY CARCINOMA, NOS, and $2.71 \%$ INTRADUCTAL CARCINOMA, NONINFILTRATING, NOS. They included $89.56 \%$ of all morphologies of breast cancer in these women. The most common morphology (INFILTRATING DUCT CARCINOMA) decreased from $81.98 \%$ in 2003 to $76.59 \%$ in 2008 , which was significant with APC equal to -1.76. Studies performed in Iran also confirmed that INFILTRATING DUCT CARCINOMA is the most common morphology (Li et al., 2003; Mousavi et al., 2007; Naghibi et al., 2013). In our study, the second common morphology was LOBULAR CARCINOMA, NOS (5.61\%), with APC of 3.6 showed a remarkable increasing trend. Other studies in Iran also stated such results (Mousavi et al., 2007). LOBULAR CARCINOMA, NOS was also the second common morphology of breast cancer in United States. The incidence of the morphology was $7.6 \%$ and increased 1.52 times from 1987 to 1999 (Li et al., 2003).

The main objective of breast imaging is breast cancer diagnosis. Mammography, as a screening test, is effective for early detection of the cancer (Berg et al., 2004). It is necessary to do regular periodic examinations and mammography in women, especially menopausal ages (Force, 2009). For detection of cancer cases, sensitivity of mammography reduces as breast density increases. In older women who have low density in their breast, diagnosis performs easier (Kolb et al., 2002). LOBULAR CARCINOMA cases are detected with lower sensitivity than DUCTAL CARCINOMA cases by mammography. Therefore, in the United States, combination of screening mammography, clinical examination, and MR imaging are used to determine the type of breast cancer (Berg et al., 2004). An increasing trend of LOBULAR CARCINOMA, NOS may be due to lack of data on patients registered in previous years, incomplete information, or incorrect diagnosis. The advancement of medical diagnostic equipment and the use of combined detection provide more accurate results of morphologies of breast cancer.

There is no screening program for breast cancer in Iran. It is expected to increase cases with increased life expectancy and changes in lifestyles in the next years. Health policy makers in developing countries should consider design and implementation of the national cancer control program in their priority (Mousavi et al., 2009).

The limitations of this study were the possibility of incomplete records or lack of information on the patients, and lack of patients' information based on rural and urban population. A part of the increasing trend of breast cancer 
may be due to improvements in registration and reporting systems during years studied.

It seems to investigate the trend of the cancer by age groups in future to carry out proper screening and providing training to people at risk. It will help control the disease in the community. Knowing trend of the cancer and its common morphologies by provinces of the country can aid to reduce the incidence rate in each province using proper planning.

\section{Acknowledgements}

The authors are thankful for contributions of those who helped them to carry out this study.

\section{References}

Almasi Z, Rafiemanesh H, Salehiniya H (2015). Epidemiology characteristics and trends of incidence and morphology of stomach cancer in Iran. Asian Pac J Cancer Prev, 16, 2757-61.

Anand P, Kunnumakkara AB, Sundaram C, et al (2008). Cancer is a preventable disease that requires major lifestyle changes. Pharm Res, 25, 2097-116.

Berg WA, Gutierrez L, NessAiver MS, et al (2004). Diagnostic accuracy of mammography, clinical examination, US, and MR imaging in preoperative assessment of breast cancer 1 . Radiol, 233, 830-49.

Chahine G,El Rassy E, Khazzaka A, et al (2015). Characteristics of incident female breast cancer in Lebanon, 1990-2013: Descriptive study of 612 cases from a hospital tumor registry. Cancer Epidemiol.

Chin TM, Tan SH, Lim SE, et al (2005). Acceptance, motivators, and barriers in attending breast cancer genetic counseling in Asians. Cancer Detect Prev, 29, 412-8.

Daubisse-Marliac L, Delafosse P, Boitard JB, et al (2011). Breast cancer incidence and time trend in France from 1990 to 2007: a population-based study from two French cancer registries. Ann Oncol, 22, 329-34.

Esteghamati A, Khalilzadeh O, Rashidi A, et al (2011). Physical activity in Iran: results of the third national surveillance of risk factors of non-communicable diseases (SuRFNCD-2007). J Physical Activity Health, 8, 27-35.

Ferlay J, Shin HR, Bray F, et al (2010). Estimates of worldwide burden of cancer in 2008: GLOBOCAN 2008. International J Cancer, 127, 2893-917.

Force UPST (2009). Screening for breast cancer: US Preventive Services Task Force recommendation statement. Ann Int Med, 151, 716.

Jemal A, Bray F, Center MM, et al (2011). Global cancer statistics. CA Cancer J Clin, 61, 69-90.

Jemal A, Center MM, DeSantis C, et al (2010). Global patterns of cancer incidence and mortality rates and trends. Cancer Epidemiology Biomarkers Prev, 19, 1893-907.

Jemal A, Ward E, Thun MJ (2007). Recent trends in breast cancer incidence rates by age and tumor characteristics among U.S. women. Breast Cancer Res, 9, R28.

Keyghobadi N, Rafiemanesh H, Mohammadian-Hafshejani A, et al (2015). Epidemiology and trend of cancers in the province of Kerman: southeast of Iran. Asian Pac J Cancer Prev, 16, 1409-13.

Kolb TM, Lichy J, Newhouse JH (2002). Comparison of the performance of screening mammography, physical examination, and breast us and evaluation of factors that influence them: an analysis of 27,825 patient evaluations 1 .
DOI:http://dx.doi.org/10.7314/APJCP.2016.17.3.1393 Age-Dependent Trends of Breast Cancer Incidence in Iran Radiol, 225, 165-75.

Li CI, Anderson BO, Daling JR, et al (2003). Trends in incidence rates of invasive lobular and ductal breast carcinoma. JAMA, 289, 1421-4.

Mehdi I, Monem EA, Al Bahrani BJ, et al (2014). Age at diagnosis of female breast cancer in Oman: Issues and implications. South Asian J Cancer, 3, 101-6.

Mousavi SM, Gouya MM, Ramazani R, et al (2009). Cancer incidence and mortality in Iran. Ann Oncol, 20, 556-63.

Mousavi SM, Montazeri A, Mohagheghi MA, et al (2007). Breast cancer in Iran: an epidemiological review. Breast $J, \mathbf{1 3}, 383-91$.

Naghibi S, Shojaizadeh D, Montazeri A, et al (2013). Epidemiology of breast cancer in mazandaran province, 2009-2010. J Mazandaran Univ Med Sci, 23, 113-20.

Rafiemanesh H, Mehtarpoor M, Mohammadian-Hafshejani A, et al (2015a). Cancer epidemiology and trends in Sistan and Baluchestan province, Iran. Med J Islamic Republic Iran, 29, 752-9.

Rafiemanesh H, Rajaei-Behbahani N, Khani Y, et al (2015b). Incidence trend and epidemiology of common cancers in the center of Iran. Global J Health Sci, 8, 146.

Razi S, Rafiemanesh H, Ghoncheh M, et al (2015). Changing trends of types of skin cancer in Iran. Asian Pacific J Cancer Prev, 16, 4955-8.

Santos SI (1999). Cancer epidemiology, principles and methods. Cancer epidemiology, principles and methods.

SascoAJ (2001). Epidemiology of breast cancer: an environmental disease? APMIS, 109, 321-32.

Saxena S, Rekhi B, Bansal A, et al (2005). Clinico-morphological patterns of breast cancer including family history in a New Delhi hospital, India--a cross-sectional study. World J Surg Oncol, 3, 67.

Tazhibi M, Dehkordi ZF, Babazadeh S (2014). Trends in breast cancer incidence rates by age and tumor characteristics of women in the city of Isfahan for the period 2001-2010: An application of joinpoint analysis. J Res Med Sci, 19, 319-25.

Vakili M, Pirdehghan A, Adimi M, et al (2014). Epidemiology and trend of cancer in yazd, a central province of iran, 20052009. J Res Health Sci, 14, 210-3.

WHO (2000). International classification of diseases for oncology: ICD-O.Geneva.

Yang L, Yuan Y, Sun T, et al (2015). Population-based cancer incidence analysis in Beijing, 2008-2012. Chin J Cancer Res, 27, 13-21. 